\title{
Differences in the transcriptome signatures of two genetically related Entamoeba histolytica cell lines derived from the same isolate with different pathogenic properties
}

\author{
Laura Biller ${ }^{1 \dagger}$, Paul H Davis ${ }^{2+}$, Manuela Tillack${ }^{1}$, Jenny Matthiesen ${ }^{1}$, Hannelore Lotter ${ }^{1}$, Samuel L Stanley $\mathrm{Jr}^{3}$,
} Egbert Tannich', Iris Bruchhaus ${ }^{1 *}$

\begin{abstract}
Background: The availability of two genetically very similar cell lines (A and B) derived from the laboratory isolate Entamoeba histolytica HM-1:IMSS, which differ in their virulence properties, provides a powerful tool for identifying pathogenicity factors of the causative agent of human amoebiasis. Cell line A is incapable inducing liver abscesses in gerbils, whereas interaction with cell line $B$ leads to considerable abscess formation. Phenotypic characterization of both cell lines revealed that trophozoites from the pathogenic cell line B have a larger cell size, an increased growth rate in vitro, an increased cysteine peptidase activity and higher resistance to nitric oxide stress. To find proteins that may serve as virulence factors, the proteomes of both cell lines were previously studied, resulting in the identification of a limited number of differentially synthesized proteins. This study aims to identify additional genes, serving as virulence factors, or virulence markers.
\end{abstract}

Results: To obtain a comprehensive picture of the differences between the cell lines, we compared their transcriptomes using an oligonucleotide-based microarray and confirmed findings with quantitative real-time PCR. Out of 6242 genes represented on the array, 87 are differentially transcribed ( $\geq$ two-fold) in the two cell lines. Approximately 50\% code for hypothetical proteins. Interestingly, only 19 genes show a five-fold or higher differential expression. These include three rab7 GTPases, which were found with a higher abundance in the nonpathogenic cell line A. The aig1-like GTPasesare of special interest because the majority of them show higher levels of transcription in the pathogenic cell line B. Only two molecules were found to be differentially expressed between the two cell lines in both this study and our previous proteomic approach.

Conclusions: In this study we have identified a defined set of genes that are differentially transcribed between the non-pathogenic cell line A and the pathogenic cell line B of E. histolytica. The identification of transcription profiles unique for amoebic cell lines with pathogenic phenotypes may help to elucidate the transcriptional framework of E. histolytica pathogenicity and serve as a basis for identifying transcriptional markers and virulence factors.

\section{Background}

The human protozoan parasite E. histolytica resides in the large bowel and can persist there for months or even years, causing asymptomatic luminal gut infection. Occasionally, E. histolytica trophozoites penetrate the intestinal mucosa, causing amoebic colitis and spread

\footnotetext{
* Correspondence: bruchhaus@bni-hamburg.de

† Contributed equally

${ }^{1}$ Bernhard Nocht Institute for Tropical Medicine, Bernhard-Nocht-Str. 74 20359 Hamburg, Germany
}

via portal circulation to other organs, most commonly to the liver, where they induce abscess formation.

Currently, the factors determining the clinical outcome of E. histolytica infection are unknown, although a number of different hypotheses have been made. Host or parasite genetic factors could play a role, but so could the nature of the immune response, as well as concomitant infections or even diet.

The mechanisms and processes that allow Entamoeba to penetrate the tissue of its host and induce colitis and 
liver abscesses are not completely understood. Several studies have dealt with the identification of pathogenicity factors of E. histolytica. In particular, the galactose/ $\mathrm{N}$-acetyl D-galactosamine-inhibitable (Gal/GalNAc) lectins, the cysteine peptidases and amoebapores have been related to pathogenicity (for review [1]). However, these molecules cannot exclusively be responsible for amoebic virulence, because they are found in pathogenic as well as in non-pathogenic E. histolytica isolates. Beside the characterization of individual molecules, different approaches comparing the transcriptomes or proteomes of virulent and non-virulent isolates have been performed. In nearly all of these studies, a comparison was made between the pathogenic E. histolytica isolate HM1:IMSS and the non-pathogenic isolate Rahman [2-5]. HM-1:IMSS was isolated in 1967 from a patient with amoebic dysentery, whereas Rahman was originally isolated in England 1973, from an asymptomatic individual. In contrast to HM-1:IMSS, Rahman does not form liver abscesses in animal models and has a defect in causing amoebic colitis in human colonic xenografts. In addition, a reduced cytotoxicity in vitro for epithelial cellsand a defect in erythrophagocytosis was observed [6,7]. However, due to the high genetic variability of $E$. histolytica isolates, differences between pathogenic and nonpathogenic isolates might simply reflect inter-isolate variation rather than specific differences linked to virulence.

To circumvent the problem of substantial genetic inter-isolate variation, we have recently analyzed two cell lines derived from the E. histolytica isolate HM-1: IMSS, called cell line A and cell line B. Genetically, both share identity in the highly polymorphic tandem repeat DNA sequences tested, but cell line B consistently produces large liver abscesses in a gerbil model of disease, whereas cell line A does not [8].

Phenotypic analysis of both cell lines revealed in cell line A an increased hemolytic activity, a lower growth rate, smaller cell size, a reduced cysteine peptidase activity and a lower resistance to nitric oxide stress. Proteomic comparison by two-dimensional difference gel electrophoresis (2D-DIGE) followed by mass spectrometry, identified a total of 21 proteins with higher abundance in cell line $A$ and ten proteins with higher abundance in cell line B. Notably, in the case of only two differentially regulated proteins, namely a Fe-hydrogenase 2 and a $\mathrm{C} 2$ domain protein, was a differential expression also found on the level of transcription [8].

Here we compare the transcriptomes of cell line A and cell line $B$ to get a more complete picture of the biomolecular differences between these cell lines. For this we used a custom 70-mer oligonucleotide-based microarray, previously applied to compare the transcriptomes of Rahman and HM-1:IMSS [3].
Our data indicate that there are significant and reproducible transcriptional differences between these cell lines. Most differentially expressed genes belong to the family of small GTPases. These are of special interest as putative $E$. histolytica pathogenicity factors, because most members of the family coding for the AIG1GTPases are upregulated in the pathogenic cell line B. On the other hand, some Rab GTPases were found in higher levels in the non-pathogenic cell line A. The determination of the specific expression profiles of the non-pathogenic cell line A and the pathogenic cell line $B$ may help provide new insights into the mechanisms that have enabled E. histolytica to become a pathogen.

\section{Results}

The aim of this work is to identify potential pathogenicity factors, by comparing the transcriptional profiles of two genetically related Entamoeba histolytica HM-1: IMSS cell lines with different virulence phenotypes.

Both cell lines are derived from the E. histolytica isolate HM-1:IMSS as both were originally obtained from the American Type Culture Collection (ATCC) under the catalogue number 30459. To examine whether the cells from the two cell lines are genetically related and indeed derived from isolate HM-1:IMSS, tRNA-linked short tandem repeat (STR) sequences from six different loci were analyzed [8].

When these cells are used for infection experiments to induce amoebic liver abscesses in gerbils, cell line $\mathrm{A}$ produces very small lesions of pin-head size only, whereas cell line B induces significant abscesses affecting up to $30 \%$ of the liver [8]. The pathogenic phenotype of cell line B appears to be a constant property as it has been maintained without any animal passage for at least five years. The stability of the phenotype was tested routinely every six month.

Comparison of the transcriptomes of $E$. histolytica cell line $A$ and cell line B

To identify differences between cell lines A and B on a molecular level, we compared their transcriptomes. For this study, a custom-made 70-mer oligonucleotide microarray was used containing 6242 unique genes found in the E. histolytica genome dataset of February 2004. The microarray data are deposited in the public database ArrayExpress http://www.ebi.ac.uk/arrayexpress under the accession number E-MEXP-2504.

Using this array and analyzing two biological replicates, 87 gene transcripts were detected that show a two-fold or greater difference in expression between cell line A and cell line B. Out of these, 47 genes were significantly upregulated in the non-pathogenic cell line $\mathrm{A}$ and 40 genes were transcribed at significantly higher levels in the pathogenic cell line B (additional file 1). 
We used quantitative real-time PCR to confirm the differential transcription of 27 selected genes that showed at least a three-fold higher level of transcription in one or other cell line. For all 27 analyzed genes, the real-time PCR results matched the microarray data (additional file 1).

Of the 87 differentially transcribed genes, 39 could be classified by putative biological function, namely stress response, trafficking/targeting, transporter, signaling, kinases, RNA/DNA metabolism, cell cycle, cell metabolism, peptidases, lectins, and AIG1 family proteins. The remaining 48 genes were categorized as genes coding for proteins of unknown function in E. histolytica (additional file 1).

Altogether, 17 of the deduced proteins of the 87 identified differentially transcribed genes contain one to eleven transmembrane domains. Interestingly, of these, five have no predicted signal peptide or signal anchor sequence, including two of the four AIG1 transcripts identified (additional file 1).

The majority of the differentially transcribed genes show only a two- to four-fold difference in expression. These include 39 genes for cell line A and 29 genes for cell line B. Only a limited number of genes (19 in total) show a five-fold or higher differential expression between the cell lines, as determined by microarray analyses and/or real time-PCR. Due to their highly significant differential expression (1000-fold in some cases), and comparative observation of nearly all other transcripts in the parasite, it is likely that these identified molecules are involved in the large difference in virulence observed between cell lines A and B. Three of the highly differentially expressed genes are rab7 gtpases, which are transcribed in higher levels in cell line A. This was confirmed using quantitative real-time PCR. Here, the differential transcription was between 50 - and 740 -fold. In addition, two genes coding for $\mathrm{C} 2$ domaincontaining proteins were also expressed in higher levels in cell line A. Like the Rab proteins, molecules containing a $\mathrm{C} 2$ domain may be involved in regulating membrane traffic pathways. Quantitative real-time PCR indicates that together with one hypothetical protein [GenBank:XM_649962], a C2 domain-containing protein shows the highest differential transcription (approximately 1000 -fold) of all analyzed genes (Table 1, additional file 1).

Furthermore, transcript levels for a cell surface protease gp63 (ehmp8-2) [GenBank:XM_647540] are also found in much higher levels in cell line A compared to cell line B (Table 1). Within the E. histolytica genome,

Table 1 List of genes differentially transcribed ( $\geq 5$-fold) in E. histolytica HM-1:IMSS cell lines A and B identified by microarray analyses and real-time PCR

\begin{tabular}{|c|c|c|c|c|c|}
\hline \multirow[t]{2}{*}{ Gene name } & \multirow[t]{2}{*}{ Accession-No. Gene } & \multicolumn{2}{|c|}{ Microarry results ( $x$-fold) } & \multicolumn{2}{|c|}{ Real time-PCR results ( $x$-fold) } \\
\hline & & Cell line $A$ & Cell line B & Cell line $A$ & Cell line B \\
\hline EhRab7E protein & XM_646110 & 62.00 & & 743.45 & \\
\hline Hypothetical protein & XM_648456 & 52.11 & & 866.52 & \\
\hline EhRab7D protein & XM_646823 & 25.37 & & 125.00 & \\
\hline EhMP8-2 (gp63) & XM_647540 & 21.44 & & 70.58 & \\
\hline C2 domain containing protein & XM_650207 & 16.65 & & 1000.00 & \\
\hline EhRab7G protein & XM_651385 & 14.50 & & 50.00 & \\
\hline C2 domain containing protein & XM_650951 & 6.62 & & 33.35 & \\
\hline Hypothetical protein & XM_644469 & 3.52 & & 5.71 & \\
\hline Hypothetical protein & XM_643681 & 3.46 & & 7.53 & \\
\hline AIG1 family protein & XM_648725 & & 14.29 & & 100.00 \\
\hline Hypothetical protein & XM_645291 & & 14.28 & & 50.00 \\
\hline AIG1 family protein & XM_645223* & & 12.50 & & 4.76 \\
\hline Hypothetical protein (AIG) & XM_648115* & & 12.50 & & 100.00 \\
\hline Hypothetical protein & XM_645139 & & 9.09 & & 5.00 \\
\hline Hypothetical protein & XM_647137 & & 8.33 & & 7.14 \\
\hline Serine-threonine-isoleucine rich protein & XM_648869 & & 6.25 & & 3.85 \\
\hline Hypothetical protein & XM_649962 & & 5.26 & & 980.00 \\
\hline Hypothetical protein & XM_646695 & & 5.3 & & 4.5 \\
\hline AIG1 family protein & XM_643009* & & 4.34 & & 100.00 \\
\hline (Fe-hydrogenase 2 & XM_647747 & & 2.44 & & $3.22)^{\#}$ \\
\hline
\end{tabular}

* Removed from NCBI

\# Identified as differential in proteomic and transcriptomic approach 
two gp63 genes are present, which are termed ehmp8-1 [GenBank: XM 650302] and ehmp8-2. These molecules show $34 \%$ identity to each other and contain both a signal peptide and a transmembrane domain. In contrast to ehmp8-2, the expression of ehmp-8-1 is similar in both isolates as indicated by microarray analyses and real-time PCR (data not shown).

Additionally, three transcripts representing hypothetical proteins were found in higher abundances in cell line A. One shows a 50-fold higher expression level in cell line A in comparison to cell line B. This gene encodes for a protein of 105 amino acids, and $80 \%$ of the protein consists of the amino acids Pro, Gly, Met, Tyr and Ala. The stretch Gyl-Ala-Tyr-Pro-Pro-Met is present four times within the sequence and homology searches indicates an approximate $50 \%$ identity to the $\mathrm{N}$-terminal region of annexins.

In the pathogenic cell line B, six genes coding for hypothetical proteins could be identified that show a 5fold or higher expression level in comparison to cell line A. For two of the respective proteins, a signal anchor as well as a transmembrane domain could be predicted (Table 1, additional file 1).

\section{Identification of the $E$. histolytica AIG1 protein family}

The oligonucleotide array that was used in this study covers about $75 \%$ of the annotated amoebic genes. It includes oligonucleotides for four putative aig1-GTPase genes, all expressed in higher levels in the pathogenic cell line B (Table 1, additional file 1). Basic Local Alignment Search Tool (BLAST) analyses indicated that the E. histolytica aig1 gene family consists of 47 members. The composed list of aig1genes includes 17 members where the RefSeq record was removed from NCBI as a result of standard genome annotation processes (Table 2). Nevertheless, some of the removed genes have been cloned in our laboratory [GenBank: XM_649824, XM_643009, XM_645223, XM_648115] and the respective sequences were also found in whole genome shotgun reads (Entamoeba histolytica HM-1:IMSS, taxid:294381). The E. histolyticaAIG1 family members show structural similarity to the GTPases of immunityassociated protein (GIMAPS)/immune-associated nucleotide-binding protein (IAN) family of AIG1-like GTPases, which are conserved between vertebrates and angiosperm plants [9]. The members of this family comprise $30-80 \mathrm{kDa}$ proteins, characterized by an AIG1 domain (a GTP-binding motif) and coiled-coil motifs. The GTP-binding motif is composed of the G1 to G5 sequences and two conserved motifs $(\mathrm{CB}$, consensus box and IAN motif) [9]. The E. histolytica AIG1 family members have a calculated molecular mass between 20 and $45 \mathrm{kDa}$. Most of the amoebic AIG1 molecules have the first three of the five GTP-binding sites. The CB motif and the IAN motif are not present within the amoebic proteins; instead they contain three specific domains, which are conserved throughout the amoebic protein family. As described for the GIMAP molecules, some amoebic AIG1 proteins have one or two putative coiled-coil domains. In addition, there is a subgroup that contains one to three $\mathrm{C}$-terminal transmembrane domains. Some of the GIMAP members also contain hydrophobic regions at the C-terminus, which are thought to be involved in membrane anchoring [9] (Table 2; Figure 1).

\section{Transcription profiles of aig1 genes in cell line $A$ and cell} line $B$

Using quantitative real-time PCR, the transcription profiles of 34 aig1 genes were analyzed. Interestingly, 18 of these analyzed genes are transcribed at higher levels in the pathogenic cell line $B$, whereas only one gene was more highly transcribed in the non-pathogenic cell line A. For three aig1 genes, the transcription level was at least 100-fold higher, and for eight genes more than 10fold higher in cell line B compared to cell line A. The transcription level of the remaining 15 genes was similar in the two cell lines (Table 2).

\section{Discussion}

In order to identify transcripts that are involved in or even responsible for pathogenicity, we compared two highly related $E$. histolytica isolates that differ substantially in their pathogenicity. The E. histolytica HM-1: IMSS cell line B is highly pathogenic and produces large liver abscesses in an animal model, whereas HM-1:IMSS cell line A appears to have lost its ability to induce abscess formation [8].

The microarray applied in this study had already been used to identify the differences between the non-pathogenic isolate Rahman and the pathogenic isolate HM-1: IMSS [3]. Using this array, which covers $75 \%$ of E. histolytica genes, $1.4 \%$ of the analyzed genes showed a twofold or greater difference in expression between cell line $\mathrm{A}$ and cell line B. Only $0.3 \%$ of the genes showed a fivefold and higher differential transcription.

Astonishingly, there is only a small overlap between our transcriptomic and proteomic studies that compare the two cell lines. Only two genes were fond to be differentially expressed both on a transcript and protein level; Fe-hydrogenase 2 [GenBank:XM_647747] at higher abundance in cell line $\mathrm{B}$ and one $\mathrm{C} 2$ domain protein [GenBank:XM_650207] at a higher abundance in cell line A [8]. A similar phenomenon was also observed when comparing the transcriptomes and proteomes of Rahman and HM-1:IMSS with each other [2,3]. Davis and colleagues identified only one molecule (alcohol dehydrogenase 3, [GenBank:XM_650038]), where the expression profile was comparable on protein and RNA levels. This discrepancy between regulation at the 


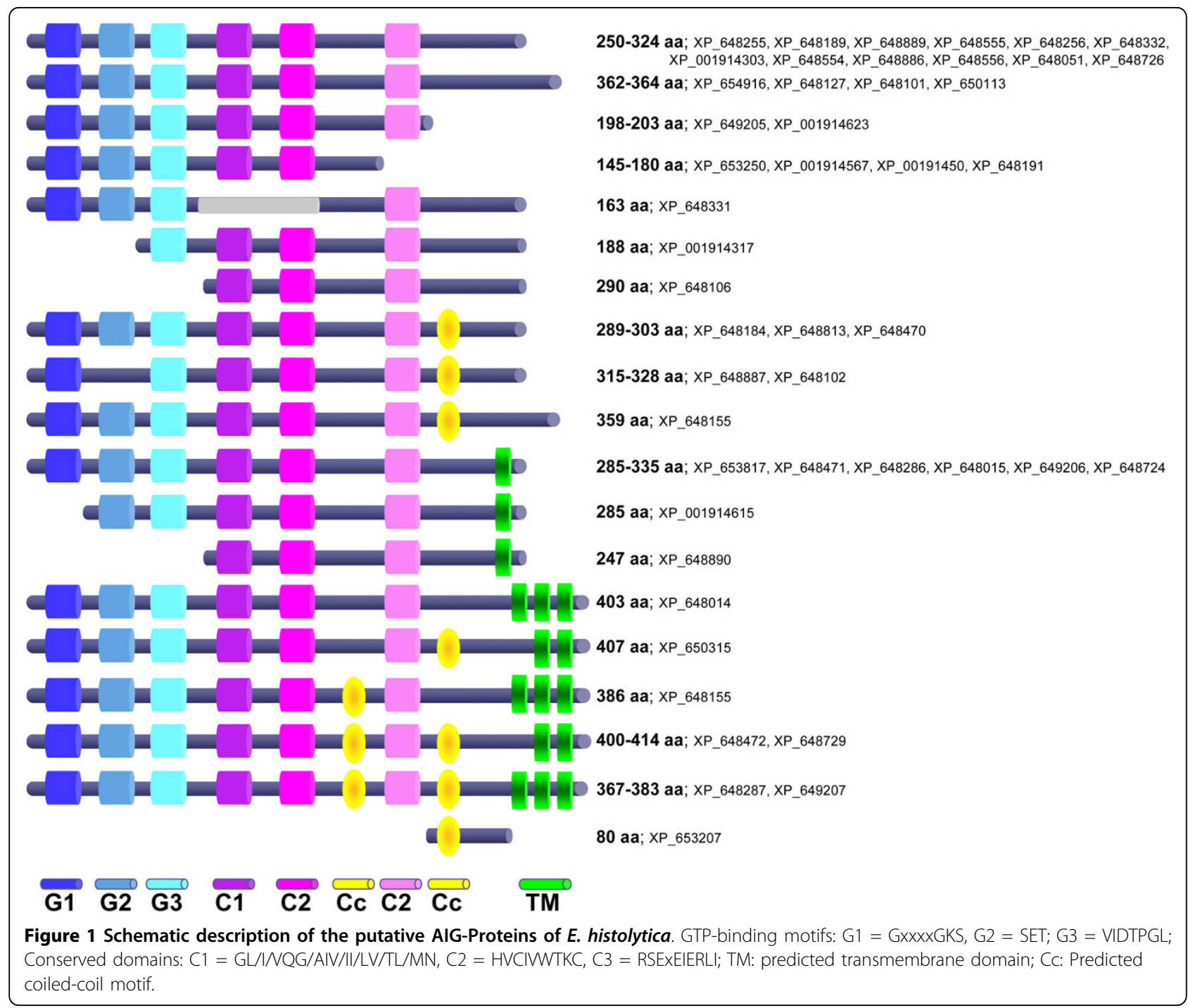

transcript- and proteome level appears therefore to be a general characteristic of Entamoeba, indicating that this primordial eukaryote has a more complex way of expression regulation.

The strategy of identifying pathogenicity genes in $E$. histolytica by comparing pathogenic and non-pathogenic strains has already been used applied by other groups. They compared the pathogenic isolate HM-1:IMSS and the non-pathogenic isolate Rahman using microarray techniques [3-5]. A direct comparison of our results with all three microarray studies exhibits only poor overlaps. Of the 152 transcripts that were found in higher levels in the pathogenic isolate HM-1:IMSS in comparison to Rahman in microarray study performed by Davis and colleagues, only five are expressed in higher levels in the pathogenic cell line B (EhCP-A4 [GenBank:XM_651510], AIG family proteins [GenBank: XM_648115, XM_643009, homolog to HSP70
[GenBank:XM_648787], hypothetical protein [GenBank: XM_648447]). We identified only one gene expressed at higher rates in the non-pathogenic cell line A (hypothetical protein [GenBank:XM_644469]) among the 201 genes that are expressed in higher levels in Rahman compared to HM-1:IMSS [3].

Only 22 of the genes found to be differentially expressed between cell line A and cell line B were also found to be regulated in the study of Ehrenkaufer and colleagues and only eleven of them are regulated in both studies in the same direction [5]. These molecules include one of the two identified $\mathrm{C} 2$ domain proteins [GenBank:XM_650951], cell surface gp63 [GenBank: XM_647540], AIG family protein [GenBank: XM_648725] and eight hypothetical proteins [GenBank:XM_645291, XM_649962, XM_644469, XM_646066, XM_647129, XM_651187, XM_645139, XM_649961]. 
Table 2 List of AIG1-like family members

\begin{tabular}{|c|c|c|c|c|c|c|c|c|c|c|c|c|c|}
\hline & $\begin{array}{l}\text { GenBank Accession } \\
\text { no. Gene }\end{array}$ & $\begin{array}{l}\text { GenBank Accession } \\
\text { no. Protein }\end{array}$ & $\begin{array}{c}\text { Size } \\
\text { aa }\end{array}$ & G1 & G2 & G3 & $\mathrm{C} 1$ & $\mathrm{C} 2$ & $\mathrm{C} 3$ & $\begin{array}{c}\mathrm{Cc}^{* *} \\
\text { (position aa) }\end{array}$ & $\begin{array}{c}\mathrm{TM}^{* * *} \\
\text { (position aa) }\end{array}$ & $\begin{array}{c}\text { Real-ti } \\
\text { data }\end{array}$ & $\begin{array}{l}\text { le PCR } \\
\text {-fold) }\end{array}$ \\
\hline & & & & & & & & & & & & $\begin{array}{l}\text { Cell } \\
\text { line } A\end{array}$ & $\begin{array}{l}\text { Cell } \\
\text { line } B\end{array}$ \\
\hline \multicolumn{14}{|l|}{$\begin{array}{l}A> \\
B\end{array}$} \\
\hline $1^{*}$ & XM_643035 & XP_648127 & 364 & + & + & + & + & + & + & & & 12.5 & \\
\hline \multicolumn{14}{|l|}{$\begin{array}{l}A< \\
B\end{array}$} \\
\hline 2 & XM_648725 & XP_653817 & 335 & + & + & + & + & + & + & & $307-324$ & & 100.00 \\
\hline $3^{*}$ & XM_643009 & XP_648101 & 364 & + & + & + & + & + & + & & & & 100.00 \\
\hline$\overline{4^{*}}$ & XM_648115 & XP_653207 & 80 & - & - & - & - & - & - & $\begin{array}{c}T h^{* * * *} 50 \%: \\
14-24 \\
\end{array}$ & & & 100.00 \\
\hline $5^{*}$ & XM_643380 & XP_648472 & 400 & + & + & + & + & + & + & $\begin{array}{l}\text { Th } 50 \%: \\
150-175 \\
262-265\end{array}$ & $\begin{array}{l}327-350 \\
372-393\end{array}$ & & 20.00 \\
\hline $6^{*}$ & XM_643637 & XP_648729 & 414 & + & + & + & + & + & + & $\begin{array}{c}\text { Th 50\%: } \\
152-174 \\
203-265\end{array}$ & $\begin{array}{l}334-360 \\
386-406\end{array}$ & & 20.00 \\
\hline 7 & XM_643379 & XP_648471 & 308 & + & + & + & + & + & + & & $284-305$ & & 16.67 \\
\hline 8 & XM_644114 & XP_649206 & 309 & + & + & + & + & + & + & & $285-306$ & & 12.50 \\
\hline 9 & XM_642923 & XP_648015 & 306 & + & + & + & + & + & + & & $283-305$ & & 11.11 \\
\hline $10^{*}$ & XM_645021 & XP_650113 & 364 & + & + & + & + & + & + & & & & 11.11 \\
\hline 11 & XM_643798 & XP_648890 & 247 & - & - & - & + & + & + & & $211-232$ & & 10.00 \\
\hline $12^{*}$ & XM_649824 & XP_654916 & 362 & + & + & + & + & + & + & & & & 10.00 \\
\hline $13^{*}$ & XM_648140 & XP_653232 & 359 & + & + & + & + & + & + & $\begin{array}{l}\text { Th } 90 \%: \\
221-235\end{array}$ & & & 5.56 \\
\hline $14^{*}$ & XM_645223 & XP_650315 & 407 & + & + & + & + & + & + & $\begin{array}{l}\text { Th } 90 \%: \\
302-313\end{array}$ & $\begin{array}{l}324-345 \\
351-369 \\
\end{array}$ & & 4.76 \\
\hline 15 & XM_643164 & XP_648256 & 304 & + & + & + & + & + & + & & & & 3.57 \\
\hline $16^{*}$ & XM_643099 & XP_648191 & 180 & + & + & + & + & + & - & & & & 2.70 \\
\hline 17 & XM_643163 & XP_648255 & 324 & + & + & + & + & + & + & & & & 2.94 \\
\hline 18 & XM_643194 & XP_648286 & 314 & + & + & + & + & + & + & & $290-311$ & & 2.63 \\
\hline 19 & XM_643240 & XP_648332 & 294 & + & + & + & + & + & + & & & & 2.63 \\
\hline \multicolumn{14}{|l|}{$\begin{array}{l}A= \\
B\end{array}$} \\
\hline $20^{*}$ & XM_643464 & XP_648556 & 304 & + & + & + & + & + & + & & & 1.25 & \\
\hline $21^{*}$ & XM_643462 & XP_648554 & 289 & + & + & + & + & + & + & & & 1.22 & \\
\hline $22^{*}$ & XM_642922 & XP_648014 & 403 & + & + & + & + & + & + & & $\begin{array}{l}288-309 \\
315-341 \\
352-374\end{array}$ & 1.12 & \\
\hline 23 & $\begin{array}{l}\text { XM_643102 } \\
\text { XM_001914071 }\end{array}$ & $\begin{array}{l}\text { XP_648194 } \\
\text { XP_001914106 }\end{array}$ & 303 & + & + & + & + & + & + & $\begin{array}{l}\text { Th 90\%: } \\
227-251\end{array}$ & & 1.06 & \\
\hline $24^{*}$ & XM_642959 & XP_648051 & 291 & + & + & + & + & + & + & & & 1.04 & \\
\hline 25 & XM_643063 & XP_648155 & 386 & + & + & + & + & + & + & $\begin{array}{l}\text { Th } 90 \%: \\
148-167\end{array}$ & $\begin{array}{l}286-313 \\
316-341 \\
348-372\end{array}$ & & 1.92 \\
\hline 26 & XM_643097 & XP_648189 & 298 & + & + & + & + & + & + & & & & 1.89 \\
\hline 27 & XM_644113 & XP_649205 & 198 & + & - & + & + & + & + & & & & 1.79 \\
\hline 28 & XM_644115 & XP_649207 & 383 & + & + & + & + & + & + & $\begin{array}{l}\text { Th } 90 \%: \\
194-208 \\
211-217\end{array}$ & $\begin{array}{l}287-308 \\
310-335 \\
341-369\end{array}$ & & 1.67 \\
\hline 29 & XM_643463 & XP_648555 & 319 & + & + & + & + & + & + & & & & 1.64 \\
\hline $30^{*}$ & XM_643100 & XP_648192 & 328 & + & - & + & + & + & + & $\begin{array}{l}\text { Th } 50 \%: \\
149-166\end{array}$ & & & 1.61 \\
\hline
\end{tabular}


Table 2: List of AIG1-like family members (Continued)

\begin{tabular}{|c|c|c|c|c|c|c|c|c|c|c|c|c|}
\hline 31 & XM_643195 & XP_648287 & 367 & + & + & + & + & + & + & $\begin{array}{l}\text { Th } 90 \%: \\
150-169 \\
196-233 \\
\end{array}$ & $\begin{array}{l}286-313 \\
315-336 \\
341-365\end{array}$ & 1.54 \\
\hline 32 & XM_643795 & XP_648887 & 315 & + & - & + & + & + & + & $\begin{array}{l}\text { Th 90\%: } \\
153-166\end{array}$ & & 1.30 \\
\hline 33 & XM_643721 & XP_648813 & 291 & + & + & + & + & + & + & $\begin{array}{c}\text { Th 50\%: } \\
195-206\end{array}$ & & 1.27 \\
\hline 34 & XM_648158 & XP_653250 & 178 & + & + & + & + & + & - & & & 1.01 \\
\hline \multicolumn{13}{|c|}{ n.d. } \\
\hline 35 & XM_643797 & XP_648889 & 287 & + & + & + & + & + & + & & & \\
\hline 36 & XM_643634 & XP_648726 & 290 & + & + & + & + & + & + & & & \\
\hline 37 & XM_001914268 & XP_001914303 & 298 & + & + & + & + & + & + & & & \\
\hline 38 & XM_643632 & XP_648724 & 308 & + & + & + & + & + & + & & $286-305$ & \\
\hline 39 & XM_001914588 & XP_001914623 & 203 & + & + & + & + & + & + & & & \\
\hline 40 & XM_001914580 & XP_001914615 & 285 & - & + & + & + & + & + & & $260-282$ & \\
\hline 41 & XM_001914532 & XP_001914567 & 145 & + & + & + & + & + & - & & & \\
\hline 42 & XM_643239 & XP_648331 & 163 & + & + & + & - & - & + & & & \\
\hline 43 & XM_001914473 & XP_001914508 & 179 & + & + & + & + & + & - & & & \\
\hline 44 & XM_001914282 & XP_001914317 & 188 & - & - & + & + & + & + & & & \\
\hline $45^{*}$ & XM_643794 & XP_648886 & 250 & + & + & + & + & + & + & & & \\
\hline $46^{*}$ & XM_643014 & XP_648106 & 290 & - & - & - & + & + & + & & & \\
\hline $47^{*}$ & XM_643378 & XP_648470 & 289 & + & + & + & + & + & + & $\begin{array}{l}\text { Th 50\%: } \\
212-241\end{array}$ & & \\
\hline
\end{tabular}

GTP-binding motifs: G1 = GxxxxGKS; G2 = SET; G3 = VIDTPGL; G4 and G5 = not present; Conserved domains: C1 = GL///VQG/AIV/II/LV/TL/MN; C2 = HVCIVWTKC; C3 = RSExEIERLI; n.d.: not determined; *Removed from NCBI; **Prediction of coiled-coil domains using Marcoil1.0 http://www.isrec.isb-sib.ch/webmarcoil/ webmarcoilC1.html[28]

***Prediction of transmembrane domains (TM) using TMHMM Server http://www.cbs.dtu.dk/services/TMHMM ****Treshold (Th)

The low level of consensus between our study comparing two cell lines with the same genetic background and the remaining studies comparing two isolates with a different genetic backgrounds, leads to the assumption that the mechanism that determine the loss of virulence in Rahman differs from that observed for HM-1:IMSS cell line A.

Interestingly, only 19 of the investigated genes $(0.3 \%$ of the predicted transcriptome) show a differential expression higher than five-fold between non-pathogenic cell line A and pathogenic cell line B. It can be assumed that genes where the level of respective transcripts differs to such an extent are involved in virulence. One of these molecules is a cell surface protease gp63 (EhMP82 ), which is transcribed at a more than 20-fold higher level in cell line A than in cell line B. In contrast to ehmp8-2, ehmp8-1 transcripts are found in similar abundance in both cell lines. In E. histolytica, neither of the gp63 proteases (EhMP8-1 and EhMP8-2) have been characterized. In Leishmania, the homolog, named leishmanolysin, occurs predominantly as a heavily-glycosylated protein that is attached to the outer membrane of Leishmaniapromastigates by a glycosylphosphatidylinositol anchor. It has been demonstrated that leishmanolysin plays a role in resistance of promastigotes to complement-mediated lysis and in receptormediated uptake of the parasite by phagocytic host cells [10]. It appears that most eukaryotes have homologs of this protein $[11,12]$.

Transcripts of three genes coding for members of the Rab7 GTPase family (EhRab7D, 7E, 7G) were detected at much higher levels in the non-pathogenic cell line A. Rab proteins are essential for the regulation of vesicular trafficking in the endocytic and exocytic/secretory pathways of eukaryotic cells [13]. E. histolytica possesses more than $90 \mathrm{rab}$ genes and therefore seems to be an organism with extremely diverse and complex Rab functions [14]. Rab7 in particular, has been described as one of the most important molecules involved in lysosomal biogenesis [15]. In different organisms it plays divergent roles in several distinct steps of endosomal or lysosomal trafficking [16]. E. histolytica encodes nine EhRab7 isotypes (EhRab7A-I), which show 40-65\% identity to each other. It was shown that EhRab7A is associated with the post-Golgi compartment and is involved in the fusion of late endosomes. EhRab7B is localized to late endosomes/lysosomes and associated with the formation of lysosomes or the fusion to lysosomes. There is further 
evidence that all the EhRab7 isotypes are sequentially and coordinately involved in phagosome biogenesis [17]. In addition, we found that Vps35, is also transcribed at higher levels in cell line A (2.6-fold). Together with Vps26 and Vps29, it forms the amoebic retromer-like complex and functions as a EhRab7A-binding protein. This retromer-like complex is linked to the retrograde transport of putative hydrolase receptors from preparatory vacuoles and phagosomes to the Golgi apparatus. Nakada-Tsukui and colleagues showed that overexpression of EhRab7A caused enlargement of lysosomes and a decrease in cellular cysteine peptidase activity. The reduced cysteine peptidase activity was restored by coexpression of EhVps26. Thus, the EhRab7A-mediated transport of cysteine peptidases to phagosomes seems to be regulated by the retromer-like complex [18]. As mentioned above, phenotypic characterization of cell line A and cell line $B$ showed a reduced cysteine peptidase activity in cell line A due to a reduced amount of mature EhCP-A1 and -A2 [8]. Although, it has been described that the interaction of EhRab7A with the retromer-like complex is specific as no association was observed with other isotypes such as EhRab7B or EhRab7D, an altered expression of molecules involved in vesicular trafficking may be responsible for the observed differences in cysteine peptidase activity [18].

We found two different transcripts of $\mathrm{C} 2$ domain-containing proteins in higher levels in the non-pathogenic cell line $\mathrm{A}$. The $\mathrm{C} 2$ domain is a $\mathrm{Ca}^{2+}$-dependent membrane-targeting module found in proteins involved in membrane trafficking. Both molecules contain one $\mathrm{N}$ terminal $\mathrm{C} 2$ domain and the $\mathrm{C}$-terminal domains show high similarity to the P30 adhesin protein of $\mathrm{Myco-}$ plasma pneumoniae and to a hypothetical protein of Paramecium tetraurelia [GenBank:XP_001426443], respectively. P30 is a membrane-bound protein that is oriented with its $\mathrm{N}$-terminus in the cytoplasm and its $\mathrm{C}$-terminus on the cell surface, and is required for cytoadherence. The protein has three types of prolinecontaining repeats at its carboxy end [19-21]. Similar repeats were also found in the $\mathrm{C} 2$ domain-containing protein of E. histolytica [GenBank:XP_655299], giving rise to an overall $56 \%$ sequence identity. Nevertheless, the amoebic molecule seems not to be membraneanchored, since it does not contain a signal sequence or a transmembrane domain. Additionally, the C-terminal region of the second $\mathrm{C} 2$-domain containing protein [GenBank:XP_656043] has a repetitive structure consisting of two main stretches.

In contrast to the transcripts described above, most members of the so far uncharacterized family of putative small GTPases, the AIG1 proteins, were found in higher levels in the pathogenic cell line B. At least 47 genes coding for AIG1 molecules are present in the $E$. histolytica genome. Quantitative real-time PCR analysis indicates that 18 of the 34 investigated aig1 genes are expressed at higher levels in cell line B. So far, the physiological relevance of these molecules is completely unknown in E. histolytica. They share partial homology to the GIMAP/IAN family molecules of vertebrates. Additionally, they have relatives in higher plants but not in most other well studied organisms, including bacteria, nematodes, and the amoeba Dictyostelium discoideum [9]. Nevertheless, aig1 genes are also present in the genome of E. invadens, E. dispar and E. moshkovskii, indicating that this family is conserved within the genus Entamoeba (data not shown). Structurally, all members of the family contain a GTP-binding cassette and several coiled-coil motifs [9]. In the E. histolytica homologs, only a part of the GTP-binding cassette is conserved and coiled-coil motifs are only predicted for some family members. GIMAP proteins are thought to be regulators of cell death in lymphomyeloid cells. It is suggested that the plant homolog AIG1 is involved in cell death regulation following self-defence responses to bacterial infection. Therefore, GIMAP proteins might be involved in self-defence machineries common to vertebrates and plants [9]. There are two further studies that discuss a link between pathogenicity and expression of aig1 genes. Davis and colleagues found aig1 genes expressed at much higher levels in HM-1:IMSS than in Rahman [3]. Additionally, the expression of aig1 genes was highly regulated in HM-1:IMSS trophozoites, obtained from a murine model of amoebic colitis. Trophozoites isolated from the cecal lumen of mice early in infection (day 1) showed either an unregulated or an increased expression of aig1 genes. Late in the infection (day 29), a decrease in the expression was observed [22]. Although this body of evidence points to an important role of aig1 genes for amoebic pathogenicity, their physiological role has to be determined.

\section{Conclusions}

The availability of two syngenic E. histolytica cell lines (A and B), which differ constantly in their virulence, provides a powerful tool to identify pathogenicity factors of the causative agent of human amoebiasis. In addition to the proteomes, which have previously been compared between the cell lines, the differences observed in the transcriptomes were analyzed in the present study using microarray technology and quantitative real-time PCR. We identified a set of genes differentially transcribed between the non-pathogenic cell line $\mathrm{A}$ and the pathogenic cell line B. Most notably, various members of a family of putative aig1 GTPase genes are transcribed at higher levels in the pathogenic cell line B, whereas some $r a b$ GTPase genes are found in higher abundance in the non-pathogenic cell line $A$. The identification of 
transcription profiles unique for amoebic cell lines with specific virulent phenotypes, may aid the understanding of the transcriptional framework of E. histolytica pathogenicity.

\section{Methods}

\section{E. histolytica cell lines and cell culture}

In this study we used two genetically related $E$. histolytica cell lines (cell line A and cell line B). Both cell lines are derived from the E. histolytica isolate HM-1:IMSS as both were originally obtained from the American Type Culture Collection (ATCC) under the catalogue number 30459. HM-1:IMSS was originally isolated from a colonic biopsy of rectal ulcer from an adult male patient with amebic dysentry in 1967, Mexico City, Mexico. The monoxenic cultured HM-1:IMSS isolate was passed from Margarita de la Torre to Louis S. Diamond who adapted it to axenic cultivation. Thereafter, this axenically cultivated HM-1:IMSS isolate was transferred to the ATCC library. Cell line A was sent to us in 2001 by Barbara Mann, Charlotteville, University of Virginia, as a batch of cells from the same culture that was used for DNA preparation to sequence the E. histolytica genome [23]. Cell line B was obtained directly from ATCC in 1991.

The identical genetic background of both cell lines was confirmed by genotyping using tRNA-linked short tandem repeats from different chromosomal loci (tRNA primers D-A5+D-A3, N-K5, N+K3, R-R5+R-R3, S ${ }^{\mathrm{TGA}}$ $\mathrm{D} 5+\mathrm{S}^{\mathrm{TGA}}-\mathrm{D} 3$ and $\left.\mathrm{S}-\mathrm{Q} 5+\mathrm{S}-\mathrm{Q} 3\right)$ as described by Ali and colleagues $[1,24]$.

Trophozoites were cultured axenically in TYI-S-33 medium supplemented with $10 \%$ adult bovine serum (ABS) at $35^{\circ} \mathrm{C}[25]$.

\section{Amebic liver abscess formation in gerbils}

An amount of $1 \times 10^{6}$ amoeba trophozoites of E. histolytica cell line A or cell line B, respectively, in a volume of $100 \mu \mathrm{L}$ were injected into the left liver lobe of eight week old male gerbils (Charles River) as previously described [26]. After seven days, sizes and weights of liver abscesses were determined. The experiment was repeated in intervals of 5-6 month during the last three years. Each time at least six gerbils were infected with cell line A or cell line B trophozoites, respectively. The cell population of both E. histolytica cell lines used for RNA extraction was tested in parallel for liver abscess formation.

\section{Microarray analyses}

For transcription comparison, we used the E. histolytica 70-base oligonucleotide two-channel microarray to analyze 6242 unique genes as described by Davis and colleagues [4].

RNA was isolated from approximately $5 \times 10^{6}$ pre-stationary phase E. histolytica cell line A and cell line B trophozoites grown in $75 \mathrm{~mL}$ culture flasks using Trizol reagent (Invitrogen) following the manufacturer's protocol. The total RNA was purified using the Qiagen RNeasy kit (Valencia, California) under modified protocol conditions without $\beta$-mercaptoethanol, including DNase treatment (Qiagen). RNA quantity and quality were obtained from an absorbance ratio at 260 and 280 nm. RNA quality was confirmed for each sample using an Agilent 2100 Bioanalyzer (Palo Alto, California) according to the manufacturer's instructions.

Cy3 or Cy5 labeled cDNA from cell line A and cell line B was cohybridized on one microarray. Altogether, four RNA samples (two biological replicates of each cell line) were competitively hybridized on four individual microarrays. Both Cy3 and Cy5 labeled cDNAs were created from each RNA sample using the Genisphere 3DNA array350 kit (Hatfield, Pennsylvania). Each pair of biological replicates was hybridized to two chips in which the Cy fluorescent channel was alternated in order to reduce dye-specific effects (dye swap). The primary and secondary cDNA hybridizations employed the 3DNA Array 350 kit for labeling, as previously described [4]. Slides were scanned on a ScanArray Express HT scanner (Perkin-Elmer, Boston, MA) to detect $\mathrm{Cy} 3$ and Cy5 fluorescence. $\log _{2}$ ratios of cell line $B$ versus cell line A samples were calculated, local background subtracted, and Loess normalized. Data analysis was accomplished with SQL scripts to calculate average and standard deviation for each transcript. Transcripts considered significant showed a 2.0-fold or more increase or decrease from control (cell line A), expression above the $10^{\text {th }}$ percentile, and a normalized standard deviation ratio (standard deviation/average) $<1$ to eliminate overly varying probes between biological and technical (dyeswapped and spotted in triplicate spotted) replicates.

\section{Quantitative real-time PCR}

$1 \times 10^{6}$ E. histolytica trophozoites were cultivated in 75 $\mathrm{mL}$ culture flasks for $24 \mathrm{~h}$. The cells were harvested via chilling on ice for $5 \mathrm{~min}$ and sedimented at $200 \times g$ for $5 \mathrm{~min}$ at $4^{\circ} \mathrm{C}$. The cells were washed twice with PBS. For isolation of total RNA trophozoites were treated with TRIZOL reagent (Invitrogen) following the manufacturer's instructions. Extracted RNA was purified using the RNeasy mini kit (Qiagen) without $\beta$-mercaptoethanol and DNA was digested with DNase (Qiagen). cDNA synthesis was accomplished with SuperScriptIII Reverse Transcriptase (Invitrogen). In a final volume of $20 \mu \mathrm{L}, 1 \mu \mathrm{g}$ of RNase-free and DNase-treated total RNA was mixed with $5 \times$ First-Strand buffer, $500 \mu \mathrm{M}$ dNTPs, 500 nM OdT-T71 (5'-GAG AGA GGA TCC AAG TAC TAA TAC GAC TCA CTA TAG GGA GAT $_{24}$ ), 2 mM DTT, 40 U RNaseOut (Invitrogen) and SuperScriptIII $(200 \mathrm{U} / \mu \mathrm{L})$. Reaction was incubated for $1 \mathrm{~h}$ at $42^{\circ} \mathrm{C}$. For quantitative real-time PCR experiments sense- and anti 
sense primer were designed by amplifying approximately 120 base pairs of the accordant gene sequences (additional file 2).

Quantitative amplification was performed in a RotorGene (Rotor-Gene 3000, Corbett) using RealMasterMix SYBR Green kit (Eppendorf). $1 \mu \mathrm{L}$ cDNA was mixed with $2.5 \times$ RealMasterMix $/ 20 \times \mathrm{SYBR}$ and $5 \mathrm{pmol} / \mu \mathrm{L}$ of appropriate sense- and anti sense primer to a final volume of $20 \mu \mathrm{L}$. Amplification conditions were as follows: 35 cycles at $95^{\circ} \mathrm{C}$ for $15 \mathrm{~s}, 58^{\circ} \mathrm{C}$ for $20 \mathrm{~s}\left(1^{\circ} \mathrm{C}\right.$ touch down for the first six cycles), $68^{\circ} \mathrm{C}$ for $20 \mathrm{~s}$ and an adjacent melting step $\left(67^{\circ} \mathrm{C}-95^{\circ} \mathrm{C}\right)$. Two biological replicates were analyzed in duplicates. Analyzing relative changes in gene expression between cell line A and cell line $B$ the $2^{-\triangle \Delta C T}$ method, provided by Rotor-Gene software was used [27]. Accordingly, cell line A was representing the calibrator cell line and actin was chosen as normalizer gene. Efficiency $\geq 0.95$ was empirically approved for selected primer and cDNA. Threshold for differentially expressed genes was set on 2.5 .

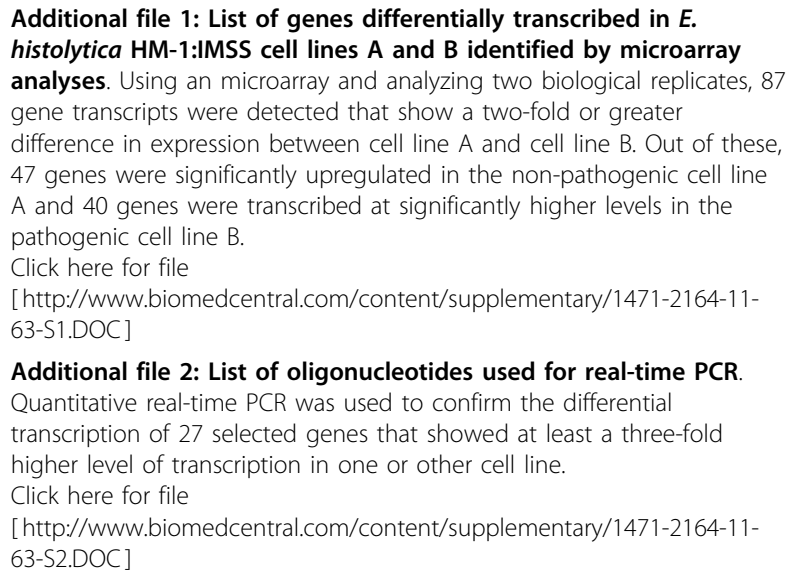

\section{Acknowledgements}

The authors would like to thank Ina Hennings and Susann Ofori for skilful technical assistance. We like to thank Rebecca Stanway for critical reading of the manuscript. This work was supported by the Deutsche Forschungsgemeinschaft (DFG, BR 1744/11-1).

\section{Author details}

'Bernhard Nocht Institute for Tropical Medicine, Bernhard-Nocht-Str. 74 20359 Hamburg, Germany. ${ }^{2}$ Department of Biology, University of Pennsylvania, Philadelphia, Pennsylvania, USA. ${ }^{3}$ Office of the President, Stony Brook University, Stony Brook, New York, USA.

\section{Authors' contributions}

$I B$ and ET conceived the study. IB coordinated the study and performed the data analysis together with $\angle B$ and PD. IB, $L B$ and ET drafted the manuscript. $L B, P D, S T, J M, H L$, and $M T$, carried out the laboratory component. All authors read and approved the final manuscript.

\section{Competing interests}

The authors declare that they have no competing interests.
Received: 3 November 2009

Accepted: 26 January 2010 Published: 26 January 2010

\section{References}

1. Clark CG, Alsmark UC, Tazreiter M, Saito-Nakano Y, Ali V, Marion S, Weber C, Mukherjee C, Bruchhaus I, Tannich E, Leippe M, Sicheritz-Ponten T, Foster PG, Samuelson J, Noel CJ, Hirt RP, Embley TM, Gilchrist CA, Mann BJ, Singh U, Ackers JP, Bhattacharya S, Bhattacharya A, Lohia A, Guillen N, Duchene M, Nozaki T, Hall N: Structure and content of the Entamoeba histolytica genome. Adv Parasitol 2007, 65:51-190.

2. Davis PH, Zhang X, Guo J, Townsend RR, Stanley SL Jr: Comparative proteomic analysis of two Entamoeba histolytica strains with different virulence phenotypes identifies peroxiredoxin as an important component of amoebic virulence. Mol Microbiol 2006, 61:1523-1532.

3. Davis PH, Schulze J, Stanley SL Jr: Transcriptomic comparison of two Entamoeba histolytica strains with defined virulence phenotypes identifies new virulence factor candidates and key differences in the expression patterns of cysteine proteases, lectin light chains, and calmodulin. Mol Biochem Parasitol 2007, 151:118-128.

4. MacFarlane RC, Singh U: Identification of differentially expressed genes in virulent and nonvirulent Entamoeba species: potential implications for amebic pathogenesis. Infect Immun 2006, 74:340-351.

5. Ehrenkaufer GM, Haque R, Hackney JA, Eichinger DJ, Singh U: Identification of developmentally regulated genes in Entamoeba histolytica : insights into mechanisms of stage conversion in a protozoan parasite. Cell Microbiol 2007, 9:1426-1444.

6. Davis PH, Zhang Z, Chen M, Zhang X, Chakraborty S, Stanley SL Jr: Identification of a family of BspA like surface proteins of Entamoeba histolytica with novel leucine rich repeats. Mol Biochem Parasitol 2006, 145:111-116.

7. Mattern CF, Keister DB, Caspar PA: Experimental amebiasis. III. A rapid in vitro assay for virulence of Entamoeba histolytica. Am J Trop Med Hyg 1978, 27:882-887.

8. Biller L, Schmidt H, Krause E, Gelhaus C, Matthiesen J, Handal G, Lotter H, Janssen O, Tannich E, Bruchhaus I: Comparison of two genetically related Entamoeba histolytica cell lines derived from the same isolate with different pathogenic properties. Proteomics 2009, 9:4107-4120.

9. Nitta T, Takahama Y: The lymphocyte guard-IANs: regulation of lymphocyte survival by IAN/GIMAP family proteins. Trends Immunol 2007, 28:58-65.

10. Tillack M, Biller L, Irmer H, Freitas M, Gomes MA, Tannich E, Bruchhaus I: The Entamoeba histolytica genome: primary structure and expression of proteolytic enzymes. BMC Genomics 2007, 8:170.

11. Yao C, Donelson JE, Wilson ME: The major surface protease (MSP or GP63) of Leishmania sp. Biosynthesis, regulation of expression, and function. Mol Biochem Parasitol 2003, 132:1-16.

12. Gomis-Ruth FX: Catalytic domain architecture of metzincin metalloproteases. J Biol Chem 2009, 284:15353-15357.

13. Zerial M, McBride H: Rab proteins as membrane organizers. Nat Rev Mol Cell Biol 2001, 2:107-117.

14. Saito-Nakano Y, Loftus BJ, Hall N, Nozaki T: The diversity of Rab GTPases in Entamoeba histolytica. Exp Parasitol 2005, 110:244-252.

15. Mullins C, Bonifacino JS: The molecular machinery for lysosome biogenesis. Bioessays 2001, 23:333-343.

16. Zhang M, Chen L, Wang S, Wang T: Rab7: roles in membrane trafficking and disease. Bioscience reports 2009, 29:193-209.

17. Saito-Nakano Y, Mitra BN, Nakada-Tsukui K, Sato D, Nozaki T: Two Rab7 isotypes, EhRab7A and EhRab7B, play distinct roles in biogenesis of lysosomes and phagosomes in the enteric protozoan parasite Entamoeba histolytica. Cell Microbiol 2007, 9:1796-1808.

18. Nakada-Tsukui K, Saito-Nakano Y, Ali V, Nozaki T: A retromerlike complex is a novel Rab7 effector that is involved in the transport of the virulence factor cysteine protease in the enteric protozoan parasite Entamoeba histolytica. Mol Biol Cell 2005, 16:5294-5303.

19. Seto S, Miyata M: Attachment organelle formation represented by localization of cytadherence proteins and formation of the electrondense core in wild-type and mutant strains of Mycoplasma pneumoniae. J Bacteriol 2003, 185:1082-1091.

20. Hasselbring BM, Jordan $J$, Krause DC: Mutant analysis reveals a specific requirement for protein P30 in Mycoplasma pneumoniae gliding motility. J Bacteriol 2005, 187:6281-6289. 
21. Varshney AK, Chaudhry R, Kabra SK, Malhotra P: Cloning, expression, and immunological characterization of the P30 protein of Mycoplasma pneumoniae. Clin Vaccine Immunol 2008, 15:215-220.

22. Gilchrist CA, Houpt E, Trapaidze N, Fei Z, Crasta O, Asgharpour A, Evans C, Martino-Catt S, Baba DJ, Stroup S, Hamano S, Ehrenkaufer G, Okada M, Singh U, Nozaki T, Mann BJ, Petri WA Jr: Impact of intestinal colonization and invasion on the Entamoeba histolytica transcriptome. Mol Biochem Parasitol 2006, 147:163-176.

23. Loftus B, Anderson I, Davies R, Alsmark UC, Samuelson J, Amedeo P, Roncaglia P, Berriman M, Hirt RP, Mann BJ, Nozaki T, Suh B, Pop M, Duchene M, Ackers J, Tannich E, Leippe M, Hofer M, Bruchhaus I, Willhoeft U, Bhattacharya A, Chillingworth T, Churcher C, Hance Z, Harris B, Harris D, Jagels K, Moule S, Mungall K, Ormond D, et al: The genome of the protist parasite Entamoeba histolytica. Nature 2005, 433:865-868.

24. Ali IK, Zaki M, Clark CG: Use of PCR amplification of tRNA gene-linked short tandem repeats for genotyping Entamoeba histolytica. J Clin Microbiol 2005, 43:5842-5847.

25. Diamond LS, Harlow DR, Cunnick CC: A new medium for axenic cultivation of Entamoeba histolytica and other Entamoeba. Trans $R$ Soc Trop Med Hyg 1978, 72:431-432.

26. Lotter H, Zhang T, Seydel KB, Stanley SL Jr, Tannich E: Identification of an epitope on the Entamoeba histolytica 170-kD lectin conferring antibodymediated protection against invasive amebiasis. J Exp Med 1997, 185:1793-1801.

27. Livak KJ, Schmittgen TD: Analysis of relative gene expression data using real-time quantitative PCR and the 2(-Delta Delta C(T)) Method. Methods 2001, 25:402-408.

28. Delorenzi M, Speed T: An HMM model for coiled-coil domains and a comparison with PSSM-based predictions. Bioinformatics (Oxford, England) 2002, 18:617-625.

doi:10.1186/1471-2164-11-63

Cite this article as: Biller et al:: Differences in the transcriptome signatures of two genetically related Entamoeba histolytica cell lines derived from the same isolate with different pathogenic properties. BMC Genomics 2010 11:63.

\section{Publish with Bio Med Central and every scientist can read your work free of charge}

"BioMed Central will be the most significant development for disseminating the results of biomedical research in our lifetime. "

Sir Paul Nurse, Cancer Research UK

Your research papers will be:

- available free of charge to the entire biomedical community

- peer reviewed and published immediately upon acceptance

- cited in PubMed and archived on PubMed Central

- yours - you keep the copyright 